\title{
FABRICATION AND CHARACTERIZATION OF NANOCLAY-REINFORCED THERMOPLASTIC COMPOSITE FILMS
}

\author{
IZDELAVA IN KARAKTERIZACIJA NANOGLINE, OJAČANE \\ S TERMOPLASTIČNIMI KOMPOZITNIMI FILMI
}

\author{
Seçil Çelık Erbaş, Suat Bahar Baştürk \\ Department of Metallurgy and Materials Engineering, Faculty of Engineering, Manisa Celal Bayar University, Muradiye, \\ Manisa, 45040, Turkey
}

Prejem rokopisa - received: 2018-04-25; sprejem za objavo - accepted for publication: 2018-10-12

doi: $10.17222 / \mathrm{mit} .2018 .086$

\begin{abstract}
A number of nanoclay/poly(methyl methacrylate) (PMMA) composite films were prepared with three different clay concentrations $(0.5 \%, 1 \%$ and $2 \%(w / \%))$ via a solution-casting process. The nanoclay was modified by applying different compatibilization techniques: mere silane surface treatment and surfactant application with the addition of a silane agent. The interlayer distances of the clay galleries were determined using X-ray diffraction (XRD) and the modifications were verified with Fourier-transform infrared spectroscopy (FTIR) analysis. The dynamic mechanical analyses (DMA) were performed to clarify the viscoelastic properties of the produced films. Morphological characterizations were carried out with a scanning electron microscope (SEM). The neat clay/PMMA composites and pure PMMA film were also used to compare the effects of the compatibilization methods. The silane-modified clay/PMMA composites exhibited the best performance, as compared to neat PMMA, by considering the storage modulus (17.7\% increase) and the glass-transition temperature (20\% increase). However, in terms of the dynamic mechanical properties, the joint implementation of these two modification techniques did not satisfy the expectations, probably due to the excess modifier and the plasticizing effect.

Keywords: nanocomposites, chemical modification, viscoelastic properties, polymer film
\end{abstract}

Avtorji so s tako imenovanim raztopno-ulivnim procesom pripravili številne kompozitne filme (tanke prevleke) na osnovi nanogline/polimetil metakrilata (PMMA) s tremi različnimi koncentracijami gline $(0,5,1$ in 2 masnih deležev). Nanoglino so modificirali z različnimi kompatibilizacijskimi tehnikami: s površinsko obdelavo s silanom $\left(\mathrm{SiH}_{4}\right)$ ter $\mathrm{z}$ aplikacijo površinsko aktivne snovi z dodatkom za tvorbo silana. Razdalje med galerijami plasti gline so določili z rentgensko difrakcijo (XRD) in modifikacije so verificirali z infrardečo spektroskopijo s Fourierjevo transformacijo (FTIR). Dinamične mehanske analize (DMA) so izvedli, da bi razjasnili viskoelastične lastnosti izdelanih filmov. Morfološke lastnosti filmov pa so okarakterizirali z vrstičnim elektronskim mikroskopom (SEM). Med seboj so primerjali izdelane kompozite glina/PMMA in čisti PMMA ter s tem ugotavljali učinkovitost kompatibilizacijskih metod. S silanom modificirani kompoziti glina/PMMA kažejo boljše lastnosti $\mathrm{v}$ primerjavi s čistim PMMA; meritev modula shranjene energije je pokazala 17,7 \% izboljšanje in temperatura prehoda $\mathrm{v}$ steklasto stanje se je povišala za $20 \%$. Vendar pa implementacija obeh tehnik modifikacije z vidika dinamičnih lastnosti ni izpolnila pričakovanj, verjetno zaradi prebitka modifikatorja in učinka plastificiranja.

Ključne besede: nanokompoziti, kemijska modifikacija, viskoelastične lastnosti, polimerni film

\section{INTRODUCTION}

The addition of nanofillers to a polymer medium results in the formation of polymer nanocomposites that exhibit significantly improved mechanical, thermal and physical properties. In composite materials, the reinforcing components with a macroscopic size always include defects. The idea behind the use of nanoparticles in composites is based on their minimal sizes, small imperfections and high aspect ratios, which provide a larger interfacial area that leads to remarkable features, as compared to neat polymer. Since the discovery of nanoclay/nylon-6 nanostructures by the Toyota research group, many researchers have revealed the unique contributions of nanoclay-based hybrids in various appli-

*Corresponding author e-mail secil.celik@cbu.edu.tr cations, such as automotive, aerospace, coating, packaging and electronics. ${ }^{1,2}$

Although silica, alumina, carbon nanotubes and graphene are widely employed in nanocomposite applications, the effects of nanoclays in composites have also attracted considerable attention due to their high surface area, low cost and ease of availability. The nanoclay minerals that show a hydrated alumina-silicate layer structure can be categorized depending on their formula, chemical structure and physical properties. Montmorillonite (MMT) is the most popular type of nanoclay and integrated with many plastics using a variety of techniques. ${ }^{3}$ Based on the literature, four main production techniques are available for the preparation of nanoclay-based composites: solution intercalation, in-situ intercalative polymerization, melt intercalation and in-situ direct synthesis. ${ }^{4}$ The dispersion level of clay platelets in the polymer matrix is extremely important 
for a strong interaction between the platelets. Phase separated, intercalated or exfoliated structures are the main morphological types observed in the literature. ${ }^{5}$ Generally, the clay minerals show a hydrophilic character, while the polymers have a hydrophobic behaviour. In order to eliminate these drawbacks, modification of the clay is performed to provide compatibility with the plastic matrix. ${ }^{6}$ Organic cations such as an ammonium ion or phosphonium ions are commonly known organic modifiers for clay minerals.

The organophilic modification process includes the exchange of interlayer inorganic cations with organic amonium salts, which leads to a widening of the interlayer distance. Thus, the basal spacing $(d)$ extends and the diffusion of polymer into the clay galleries becomes possible. $^{7}$

Chen and Yoon revealed the effects of the silanization process on the exfoliation degree of various nanoclaybased composites. They concluded that the treatment of different organically modified clay minerals with glycidyloxypropyltrimethoxysilane increased the hydrophobicity of clay. ${ }^{8}$ Ianchis et al. performed similar research and they compared the influences of four alkoxysilanes. Based on their findings, the glass-transition temperatures $\left(T_{\mathrm{g}}\right)$ of the nanostructures were significantly affected by the modification of clay with various silane coupling agents. ${ }^{9}$ Unnikrishnan et al. concentrated on the thermal, mechanical and flammability properties of Cloisite-type nanoclay/PMMA composites. Based on their study, the addition of nanoparticles resulted in an increase of the basal spacing, which is an indication of intercalation and/or exfoliation.

The incorporation of maleicanhydride (MA) led to an increase of the thermal stability and $T_{\mathrm{g}} .{ }^{10}$ Salahuddin studied the effect of an organoclay addition on the mechanical properties of PMMA-based composites. Independent of the filler concentration, both the hardness and Izod impact strength values increased, while the tensile properties were enhanced only for a certain clay content. ${ }^{11}$

Vasiliu and her co-workers investigated the optical transparency characteristics of PMMA/MMT films. According to their results, the layered silicate/PMMA films had an optical transmission of greater than $80 \%$ in the visible-light region. ${ }^{12}$ Karesoja et al. reported the dynamic mechanical (DMA) properties of MMT/Poly (BuA-co-MMA) nanocomposite films. In their study, the clay content increase did not significantly affect the storage and loss modulus of composite films, as well as $T_{\mathrm{g}}{ }^{13}$ Kumar et al. noticed the rheological, flammability and dynamic mechanical (DMA) features of PMMAbased nanocomposites with/without a compatibilizer. It was observed that the compatibilizer promoted the interfacial bonding, which led to an increase in $T_{\mathrm{g}}$ as well as optical clarity and flammability. ${ }^{14}$ In the study of Huang and Brittain, the MMT/PMMA nanocomposite structures exhibited considerable improvements in both
$T_{\mathrm{g}}$ and decomposition temperatures. ${ }^{15}$ Deng et al. used a new initiator potassium diperiodatocuprate $\left(\mathrm{Cu}^{3+}\right)$ and according to their experimental results, the $\left(\mathrm{Cu}^{3+}\right)$ exhibited a significant role in the integration and intercalation of PMMA chains into OMMT layers. ${ }^{16}$ Khajehpour et al. focused on the thermal and morphological properties of silane-modified montmorillonite (Mnt) based fluoroelastomer (FKM) composites. Based on the XRD results, an approximately $169 \%$ increase in the basal spacing was found with reasonably good dispersion. ${ }^{17}$

The main motivation of this study is the application of an organophilic modification and silane surface treatment to the same composite films to combine their synergetic effects. Thus, two modification methods (silane agent treatment or silane agent+surfactant application joint modification) with three different clay concentrations $(0.5,1$ and 2$) \%$ were studied. After the modification process, the nanoclay and host PMMA were integrated with a conventional solution-casting method. During the work, the effects of the amount of nanoclay on the dynamic mechanical properties of the composite samples were investigated, as well as their dispersion characteristics. The resulting properties of both the pure PMMA and the produced nanocomposite films were evaluated by considering the FTIR, XRD, DMA and SEM techniques.

\section{EXPERIMENTAL PART}

\subsection{Materials}

The polymethylmethacrylate (PMMA), tetrahydrofurane (THF), cetyltrimethylammonium bromide (surfactant) and bentonite nanoclay were purchased from Merck $^{\mathrm{TM}}$. The 3-glycidyloxypropyltrimethoxysilane agent for the modification of the powder phase was supplied by Dow Corning TM.

\subsection{Modification of nanoclay powder}

In this study, two modification strategies were carried out for the nanoclay powders. In the first process, $4 \mathrm{~g}$ of nanoclay was added to an ethanol $(380 \mathrm{~mL})$ and water $(20 \mathrm{~mL})$ mixture for $30 \mathrm{~min}$ to allow the hydrolysis reaction. After that, $4 \mathrm{~g}$ of 3-glycidyloxypropyltrimethoxysilane was added to this mixture dropwise. The mixing speed was then maintained for $30 \mathrm{~min}$ in a homogenizer at $12,000 \mathrm{~min}^{-1}$ and for $15 \mathrm{~min}$ in a probe, ultrasonically tuned to $80 \%$ amplitude. The mixture was filtered and washed with ethanol, and then dried in an oven at $80{ }^{\circ} \mathrm{C} .{ }^{18}$

Bentonite clay was modified by using cetyltrimethylammonium bromide as an intercalating agent (Figure 1). For this purpose, $1 \mathrm{~g}$ of nanoclay was added to a $100-\mathrm{mL}$ methanol $(90 x / \%)$ and water $(10 x / \%)$ mixture and stirred at $70{ }^{\circ} \mathrm{C}$ until all the clay particles dispersed in the solvent. Unlike the first process, $1 \mathrm{~g}$ of surfactant (cetyltrimethylammonium bromide) was 


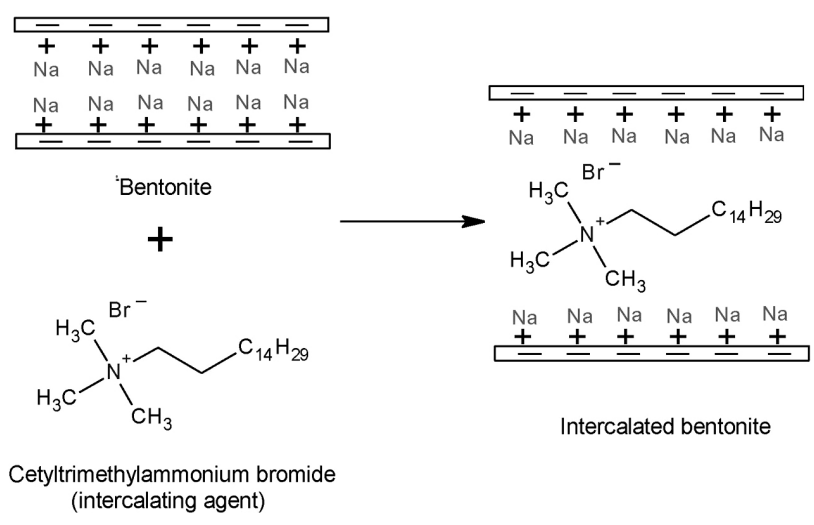

Figure 1: Bentonite intercalation with cetyltrimethylammonium bromide

added to this mixture and stirred for $1 \mathrm{~h} .1 \mathrm{~g}$ of 3-glycidyloxypropyltrimethoxysilane was introduced dropwise and the mixture was blended for $4 \mathrm{~h}$ at the same temperature. The final mixture was filtered and washed with methanol, and then dried in an oven at $80{ }^{\circ} \mathrm{C} .{ }^{17}$

\subsection{Production of PMMA/nanoclay composites}

Both the neat PMMA and PMMA/nanoclay composite films were prepared using the solution-casting technique. During the pure polymer film production, $2 \mathrm{~g}$ of PMMA and $40 \mathrm{~mL}$ of THF were mixed and stirred at $90{ }^{\circ} \mathrm{C}$ for $10 \mathrm{~min}$. After the dissolution of all the PMMA, the mixture was poured into a clean petri dish. Following the solvent's evaporation in an oven at $70{ }^{\circ} \mathrm{C}$, the produced PMMA film was stripped out from the petri dish.

A similar treatment was also carried out for the composite specimen's preparation. Modified or unmodified clay powders with three different weight percentages $(0.5 \%, 1 \%$ and $2 \%)$ were added to the prepared PMMA solution according to the above procedure. After stirring for a while with the magnetic stirrer, the mixtures were poured into the petri dish. The petri dish was sonicated for a while to provide a homogeneous distribution of the clay particles. The PMMA/nanoclay composite film was obtained after the evaporation of the mixture in the oven.

\subsection{Characterization}

The Fourier transform infrared spectrum (FTIR) analyses were performed with an Agilent ${ }^{\mathrm{TM}}$ Technologies/Cary 660 FTIR spectrophotometer to confirm the different functional peaks in the nanocomposites. The $\mathrm{X}$-ray diffraction (XRD) profiles were measured with a Panalytical Empyrean ${ }^{\mathrm{TM}}$ with $\mathrm{Cu}-\mathrm{K}_{\alpha}$ radiation $(\lambda=$ $0.15406 \mathrm{~nm}$ ) and the patterns were recorded for the $2 \theta$ range $1^{\circ}-10^{\circ}$ with a $0.01 \mathrm{~s}^{-1}$ scan speed. The basal spacings of the modified and neat clay powders were estimated from the $d(001)$ peaks in the XRD pattern. The DMA characteristics of the film specimens were assessed with $\mathrm{TA}^{\mathrm{TM}}$ Instrument Q800 equipment. The rectangular test specimens were deformed via the dual cantilever mode from $40{ }^{\circ} \mathrm{C}$ to $150{ }^{\circ} \mathrm{C}$ with a heating rate of $5{ }^{\circ} \mathrm{C} / \mathrm{min}$ under a liquid-nitrogen flow. The storage modulus $\left(E^{\prime}\right)$, loss modulus $\left(E^{\prime \prime}\right)$ and loss tangent $(\tan \delta)$ of each sample were recorded at a frequency of $1 \mathrm{~Hz}$. Morphological studies of the nanocomposite films were carried out with a COXEM ${ }^{\mathrm{TM}}$ EM-30 Plus scanning electron microscope (SEM).

\section{RESULTS AND DISCUSSION \\ 3.1 Characterization of the Modification Effects}

In order to reveal the effects of the silane surface modification and the surfactant application, the FTIR spectra of the original neat nanoclay, silanized nanoclay and surfactant-silanized nanoclay powders were recorded in the range 4000-400 $\mathrm{cm}^{-1}$ and shown in Figure 2.
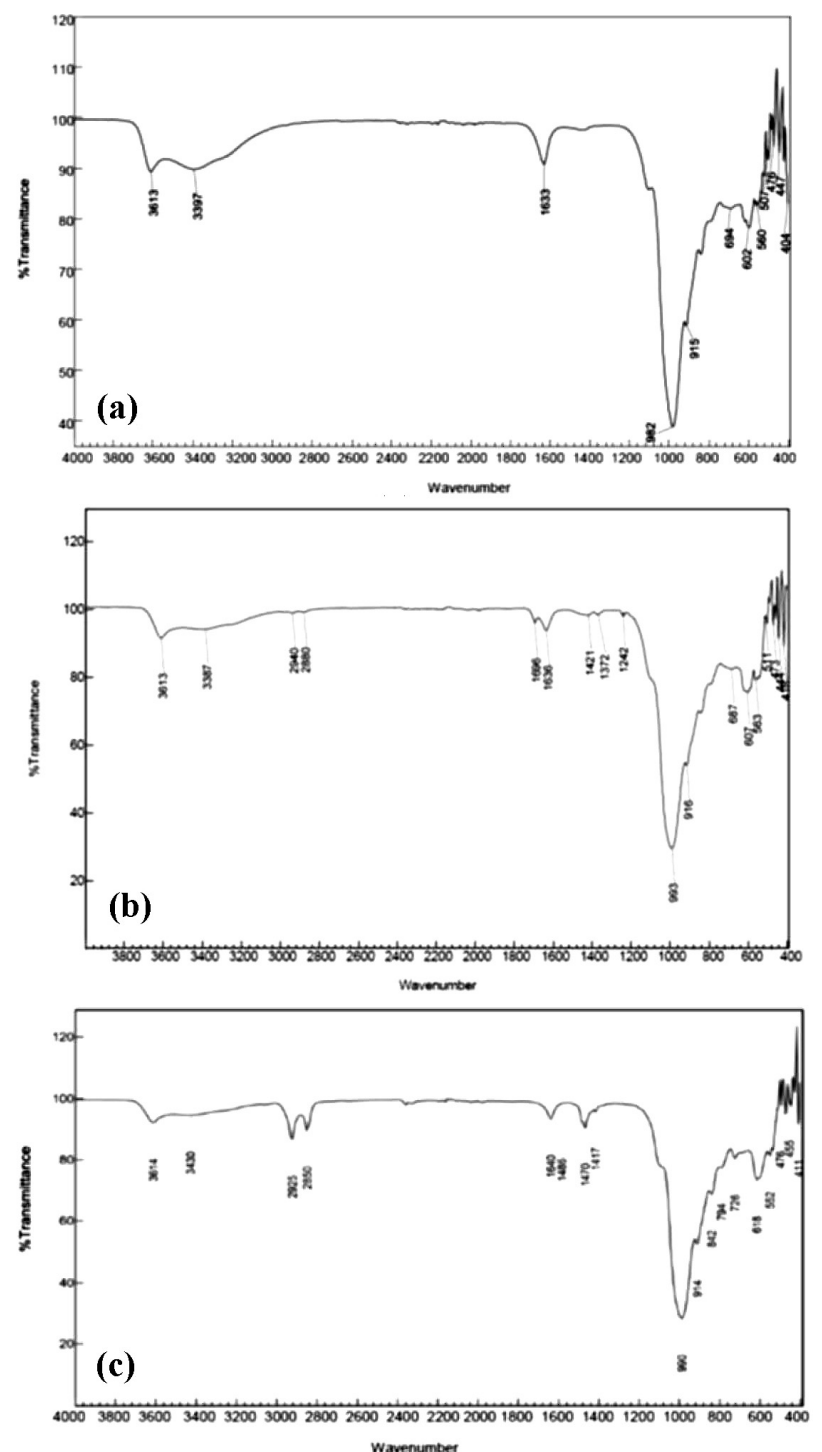

Figure 2: FTIR spectra of: a) neat nanoclay, b) silanized nanoclay and c) surfactant-silanized nanoclay 


\section{S. ÇELIK ERBAŞ et al.:FABRICATION AND CHARACTERIZATION OF NANOCLAY-REINFORCED THERMOPLASTIC ...}

There are some characteristic bands that can be seen in all the spectra (Figure 2, a), b) and c)) at approximately $3300 \mathrm{~cm}^{-1}$ and $3600 \mathrm{~cm}^{-1}$. These peaks can be described as $\mathrm{Al}-\mathrm{OH}$, Si-OH bond-stretching vibrations (peaks found in silanized and pure clay) and stretching-bending vibrations of the water $\left(\mathrm{H}_{2} \mathrm{O}\right)$ between the clay layers. A pair of strong bands, $2856 \mathrm{~cm}^{-1}$ and 2929 $\mathrm{cm}^{-1}$, were observed on modified bentonite, which could be assigned to the symmetric and asymmetric stretching vibrations of the methylene group $\left(v \mathrm{CH}_{2}\right)$. Furthermore, their bending vibrations between $1486 \mathrm{~cm}^{-1}$ and 1470 $\mathrm{cm}^{-1}$ that supported the intercalation of surfactant molecules between the silica layers was not observed in the neat clay.

The X-ray profiles of the materials provide considerable information about their dispersion grades. Based on the literature, the bentonite nanoclay generally exhibited its characteristic peak(s) between $1^{\circ}$ and $10^{\circ} ; 19,20$ therefore, during the study this range was generally taken into account in terms of the XRD interpretation. The analysis results of the pure clay, silanized clay and surfactant-silanized clay are shown in Figure 3. Depending on these spectra, the unmodified nanoclay exhibited a characteristic peak at $5.984^{\circ}$ with a $d$-spacing of $1.4981 \mathrm{~nm}$. As seen in the same figure, the merely silane surface modification slightly reduced the $2 \theta$ value to $5.757^{\circ}$ when the interlayer spacing increased to $1.5337 \mathrm{~nm}$. In addition to that the peak showed a lower intensity and broadening character that can be the attributed to the intercalation of the clay platelets. In the XRD graph of the surfactant-silanized nanopowder, an interesting hump appeared at a $2 \theta$ angle that is equivalent to $0.3993 \mathrm{~nm}$. A few researchers encountered this kind of profile in the literature and they considered the hump as an indication of an amorphous phase. ${ }^{21}$ Thus, it can be concluded that the surfactant and silane agent application resulted in the existence/increase of amorphous content.

\subsection{Dynamic mechanical properties of nanocomposi- tes}

The viscoelastic properties of the films produced using the solution-casting technique were determined

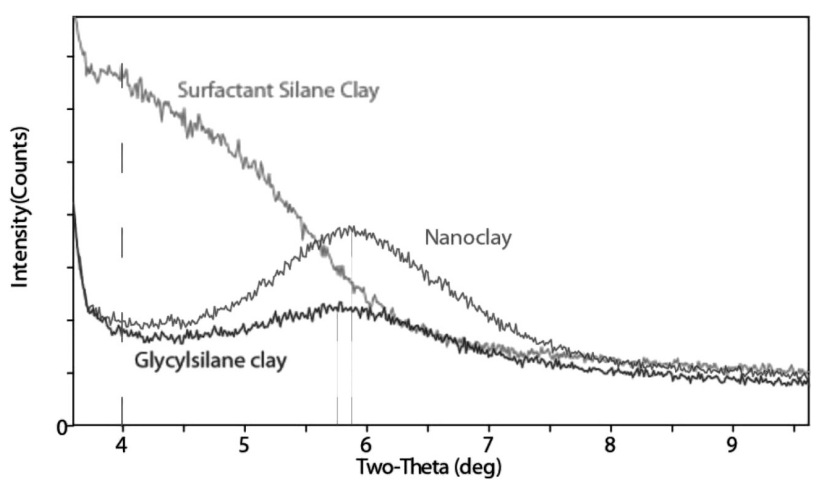

Figure 3: XRD spectra of pure nanoclay, silanized nanoclay and surfactant-silanized nanoclay with DMA to clearly compare the effects of the nanoclay addition under cycling stress at various temperatures. In Figure 4, both the storage modulus ( $\left.E^{\prime}\right)$ and the damping $(\tan \delta)$ parameters are plotted as a function of the temperature. Although the data were recorded between $40{ }^{\circ} \mathrm{C}$ and $150{ }^{\circ} \mathrm{C}$, the temperature axis ends at $120{ }^{\circ} \mathrm{C}$ to clearly identify the results of the parameters. In these graphs, the modification types were compared by considering the same nanoclay percentage.

It is evident that the major differences in the preparation procedure for the nanoclay-based composites as well as extensive variations of nanoclay type (mass, platelet size, aspect ratio, homogeneous distribution, etc.) can result in differences in the mechanical pro-
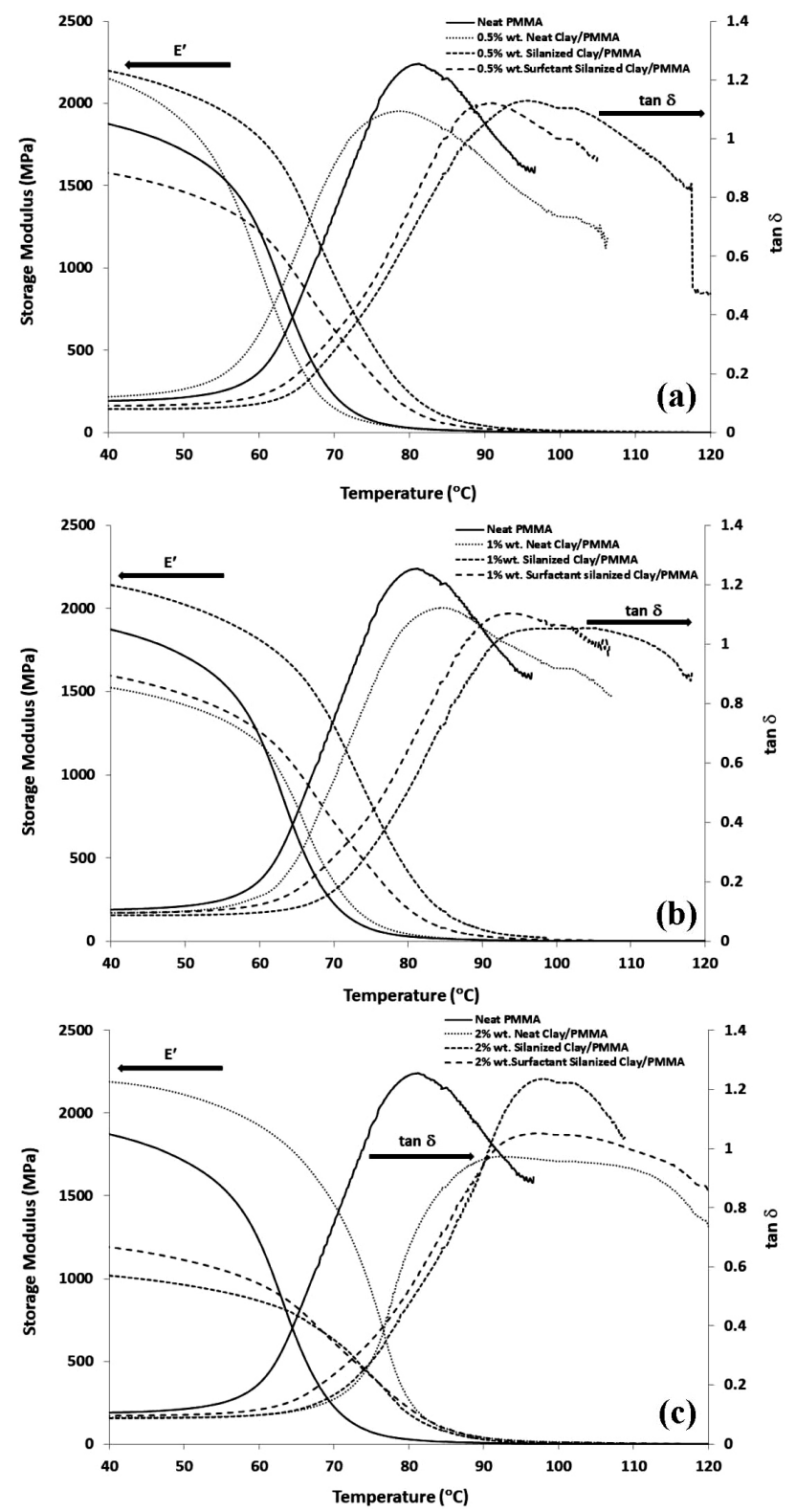

Figure 4: Storage modulus and tan delta plots containing neat PMMA and a) $0.5 \%$ nanoclay/PMMA composite, b) $1 \%$ nanoclay/ PMMA composite, c) $2 \%$ nanoclay/PMMA composite 
perties. Therefore, in this work, the individual influence of the modification method and the clay amount are considered to accurately describe the DMA properties. As seen in Figure $\mathbf{4 a}$ to $\mathbf{4 c}$, the storage modulus $\left(E^{\prime}\right)$ decreases as the temperature increases. It is observed that above $55-60{ }^{\circ} \mathrm{C}$, the decline of $E$ ' is more significant for all of the samples and $\tan \delta$ starts to rise due to the onset of a transition from the glassy state to the rubbery state. The measured modulus values of neat PMMA and the composite films are tabulated in Table 1. It is concluded from the table that the $E^{\prime}$ parameter shows unstable changes depending on the modification technique. The joint effects of the silane treatment and the surfactant application did not satisfy the expectations in terms of $E^{\prime}$. This may be explained by the adverse influence of the double modification, which probably decreased the capability of PMMA to penetrate the clay platelet spacings and caused the stiffness reduction of the composites. It might also be the fact that some of the excess modifier migrated from the nanoclay to the polymer, led to a negative plasticizing effect and resulted in the lower dynamic mechanical properties. ${ }^{22,23}$ The existence of the amorphous phase, which reduces the rigidity of materials, in the surfactant-silanized clay powder can be another possible reason for the lower $E$ 'values.

Table 1: Glass-transition temperatures $\left(T_{\mathrm{g}}\right)$ and storage moduli ( $\left.E^{\prime}\right)$ of neat and composite films based on dynamic mechanical analyses.

\begin{tabular}{|c|c|c|c|}
\hline $\begin{array}{l}\text { Amount of } \\
\text { clay }(w / \%)\end{array}$ & Sample & $\begin{array}{l}T_{\mathrm{g}} \\
\left({ }^{\circ} \mathrm{C}\right)\end{array}$ & $\begin{array}{l}E^{\prime} @ 40 \\
{ }^{\circ} \mathrm{C}(\mathrm{MPa})\end{array}$ \\
\hline 0 & Neat PMMA & 80.6 & 1871.57 \\
\hline \multirow{3}{*}{0.5} & Neat clay/PMMA comp. & 78.81 & 2192.34 \\
\hline & $\begin{array}{l}\text { Silanized clay/PMMA } \\
\text { comp. }\end{array}$ & 94.98 & 2201.98 \\
\hline & $\begin{array}{l}\text { Surfactant-silanized } \\
\text { clay/PMMA comp. }\end{array}$ & 90.45 & 1575.20 \\
\hline \multirow{3}{*}{1} & Neat clay/PMMA comp. & 83.91 & 1527.64 \\
\hline & $\begin{array}{l}\text { Silanized clay/PMMA } \\
\text { comp. }\end{array}$ & 95.17 & 2141.78 \\
\hline & $\begin{array}{l}\text { Surfactant-silanized } \\
\text { clay/PMMA comp. }\end{array}$ & 93.20 & 1592.01 \\
\hline \multirow{3}{*}{2} & Neat clay/PMMA comp. & 90.86 & 2193.66 \\
\hline & $\begin{array}{l}\text { Silanized clay/PMMA } \\
\text { comp. }\end{array}$ & 96.68 & 1017.21 \\
\hline & $\begin{array}{l}\text { Surfactant-silanized } \\
\text { clay/PMMA comp. }\end{array}$ & 95.76 & 1188.14 \\
\hline
\end{tabular}

The silanized films usually exhibited higher modulus values, except for the $2 \%(w / \%)$ sample, as compared to the neat PMMA and other composite types. The treatment of nanoclay with silane leads to a reaction between the alkoxysilane Si-O-R functionalities with hydroxyl groups on the edges of the clay and promotes the $\mathrm{Si}-\mathrm{O}-\mathrm{Si}$ bridges by removing alcohols (R-OH). ${ }^{17,24}$ Therefore, the maximum $E^{\prime}$ values are attributed to the strong bonding formed between the host polymer and the silanized nanoclay.

The stiffnesses of the neat clay/PMMA composites were also investigated and it is surprising that the storage moduli of the films $(0.5 \%$ and $2 \%)$ are relatively good. The $E$ ' values of these films are close to the silanized samples and this situation might be due to the high aspect ratio of the filler and the relatively good dispersibility.

Generally, the mutual effect between the polymer chains and the nanoparticle surface promotes the generation of the polymer nanolayer close to the nanoparticle surface that determines the glass-transition temperature $\left(T_{\mathrm{g}}\right){ }^{25}$ Therefore, the vigorous interaction established between the composite components results in the improvement of this parameter. In terms of the damping characteristics of composite films, the $T_{\mathrm{g}}$ values of all the samples were measured as the peak value of a tan $\delta$-temperature plot. The single $\tan \delta$ peak's existence indicates the pure amorphous structure of the polymer nanocomposites, as seen in Figure 4a to 4c. Almost all the curves in this figure shifted towards the higher transition temperature, compared with the pure polymer due to the restricted polymer chain motion at the clay-polymer interface. As it is well known that if the $T_{\mathrm{g}}$ value of the interphase is below than matrix the prepared composite possesses a lower glass-transition temperature. In the opposite situation, the composite shows a higher $T_{\mathrm{g}}{ }^{26}$ In this study, whole nanocomposites independent of modification type (except $0.5 \%$ neat nanoclay/PMMA sample) exhibit a higher $T_{\mathrm{g}}$, which can be attributed to the strong link between the PMMA and the nanoclay in the interphase region. The $0.5 \%$ wt. neat nanoclay/ PMMA shows a lower $T_{\mathrm{g}}$ as compared to the neat PMMA, which is probably due to the smaller interfacial interaction of the components throughout the interphase zone. The increase of the clay content also considerably enhances the glass-transition temperatures of the composite films, as seen in Table 1. These results clearly showed that the introduction of more nanoclay promotes the adhesion of the polymer and layered silicate, which is a typical effect for the inclusion of clay in a polymer medium. Furthermore, the individual silanization led to the highest transition temperatures, which might be due to the advanced interaction/intercalation between the nanoclay and the PMMA via hydrogen bonding. Although the $2 \%$-silanized-clay-based nanocomposite sample showed a very low storage modulus, its $T_{\mathrm{g}}$ value increased up to $96.68{ }^{\circ} \mathrm{C}$, with an approximately $20 \%$ increase. Similar achievements for the same percentage of filler were also observed for the surfactant-silanized clay/PMMA and the neat clay/PMMA films with $18.8 \%$ and $12.73 \%$ increments, respectively.

Based on the literature, the decrease of the $\tan \delta$ peak is an indication of the reinforcement efficiency and related to the degradation of mobile chains during the glass transition. ${ }^{5}$ Regarding Figure 4, nearly all the nanocomposite films exhibited lower $\tan \delta$ peak values, as expected. This may be attributed to the chemical and physical absorption of the polymer molecules on the particle surface, which resulted in the diminishing of the 
chain mobility. 5,25 Some composites, such as the $1 \%$ silanized clay/PMMA, the $2 \%$ neat clay/PMMA and the $2 \%$ surfactant-silanized clay/PMMA, showed broad transition zones, unlike the other specimens. This type of character is generally observed when the structure possesses heterogeneity and a broader distribution of the relaxation times. ${ }^{27}$

In DMA studies, the loss modulus $\left(E^{\prime \prime}\right)$ represents the viscous features of the samples as a function of time, temperature or frequency. The loss modulus vs. temperature graphs of the produced films are seen in Figures $\mathbf{5 a}$ to 5c. As seen in the figures, the loss modulus of the pure PMMA shows a single peak that points out its amorphous nature. The $E^{\prime \prime}$ peaks of the composite films are shifted to higher temperatures with the introduction
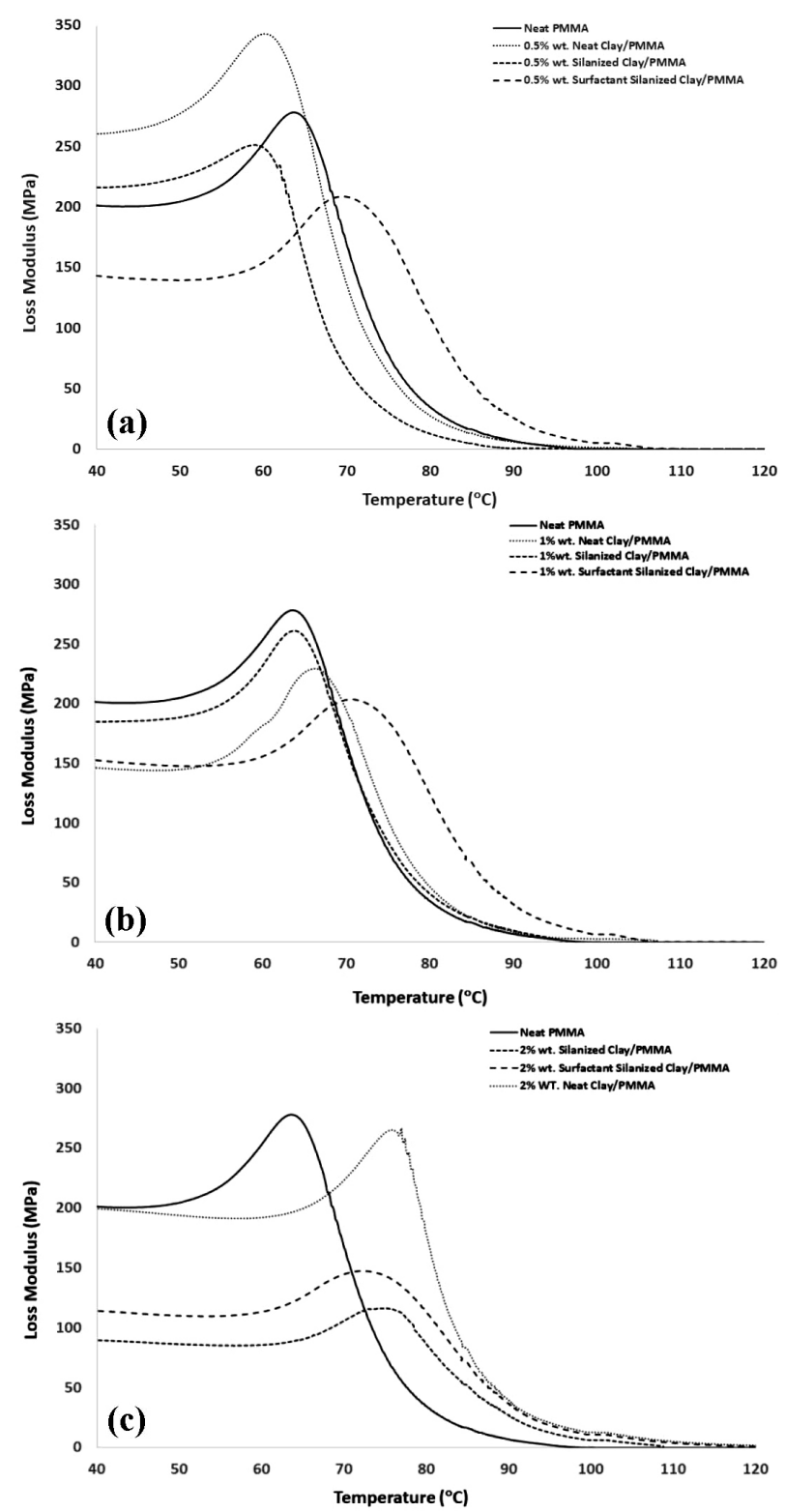

Figure 5: Loss modulus vs. temperature plots containing neat PMMA and a) $0.5 \%$ nanoclay/PMMA composite, b) $1 \%$ nanoclay/PMMA composite, c) $2 \%$ nanoclay/PMMA composite of more nanoclay, independent of the modification type. This effect may be due to the influence of the present clay on the relaxation manner of the PMMA chains. ${ }^{28}$ Another important finding is related to the loss modulus behaviour of surfactant-silanized clay-based films. Except for the $2 \%$ sample, those composites showed the highest loss transition temperatures, but lower modulus values. So it can be concluded that the improved loss modulus is a typical indication of the dominant viscous character of surfactant-silanized composites.

\subsection{Morphological characterization}

The scanning electron microscope (SEM) images of the neat PMMA and the nanoclay-based composites are shown in Figures 6 and 7. During the SEM analysis, it was difficult to capture the photographs with a fine/ precise resolution. Therefore, the whole images do not have the same magnifications. Although the intercalation or dispersion of the clay platelets in the polymer medium is not sufficiently determined from these micrographs, the distribution of filler provides fundemental ideas in terms of the morphological aspects. The clay particles in the matrix are lighter and generally observed as agglomerations or aggregates, as seen in Figure 6. Probably, they can be regarded as tactoids, which are composed of unseparated clay galleries. However, these agglomerated particles usually show a narrow size distribution and relatively good regularity.

In Figure 7a, the $2 \%$ silanized clay/PMMA film exhibited a dendritic like morphology, unlike the other samples, which resulted in the highest $T_{\mathrm{g}}$. The formation of the dendritic morphology is not as common as intercalated or exfoliated microstructures. According to the literature, ${ }^{29}$ a long or strong ultrasonic treatment promotes the transformation of self-assembled lengthy rod structures into the shortened morphologies. The mechanism consists of the fracturing of lengthy rods and
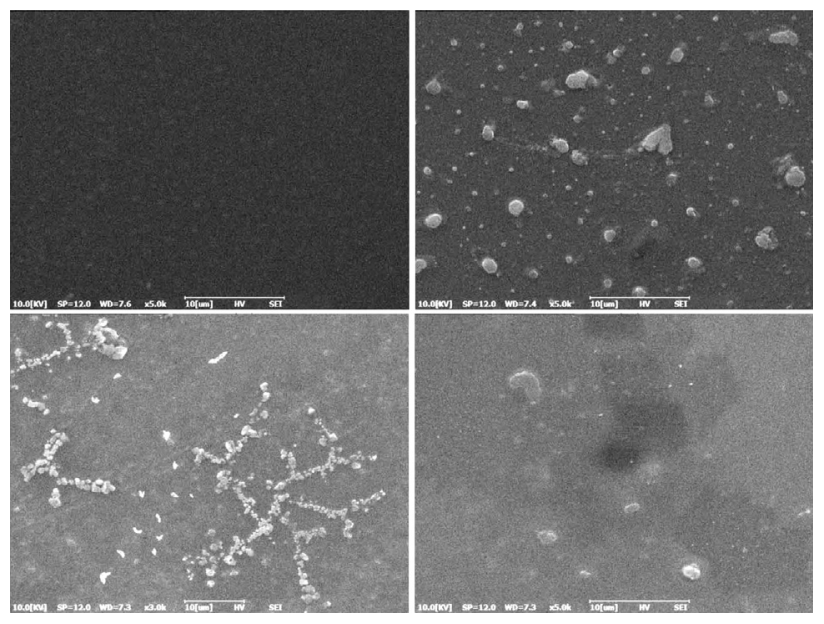

Figure 6: SEM photographs of: a) Neat PMMA, b) $0.5 \%$ silanized clay/PMMA, c) $0.5 \%$ surfactant-silanized clay/PMMA and d) $0.5 \%$ neat clay/PMMA 

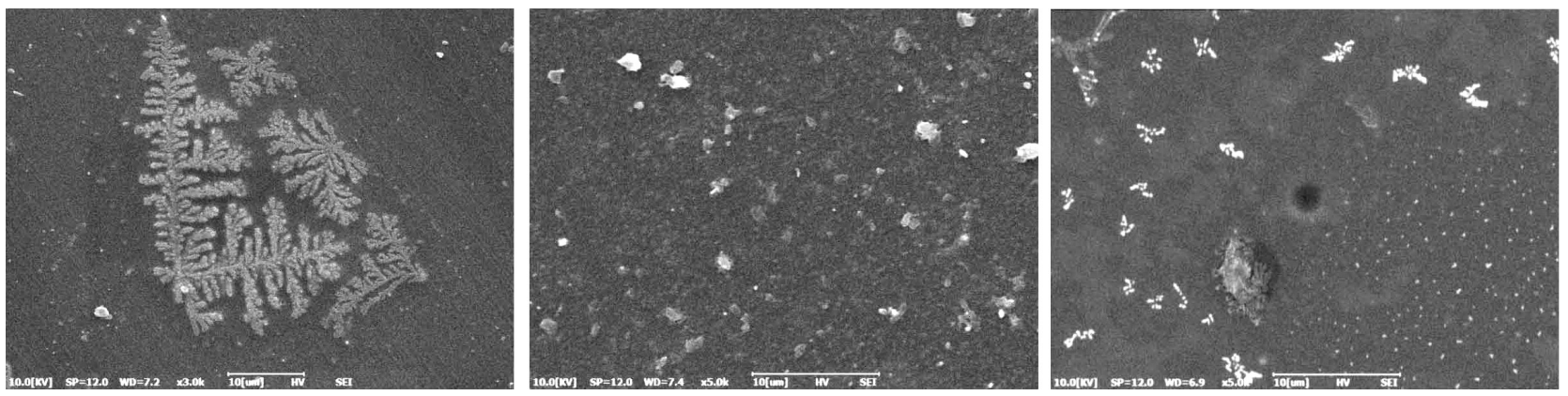

Figure 7: SEM photos of: a) $2 \%$ silanized clay/PMMA, b) $2 \%$ surfactant-silanized clay/PMMA and c) $2 \%$ neat clay/PMMA

restacking into dendrites of short rods. The ultrasonic treatment ensures sufficient energy for the hierarchical transformation and the appearance of the dendrites becomes more regular in branching. In our study, the $2 \%$ silanized clay/PMMA was probably subjected to higher ultrasonic vibration and due to the higher filler concentration, the particles tended to form leaf dendrites. This type of structure led to the increase of $T_{\mathrm{g}}$ and the decrease of the storage modulus.

The agglomerated morphology is more dominant for the other composite specimens, as seen in Figures $\mathbf{7 b}$ and 7c. Similar morphologies like in Figure 7 were also present for the $1 \%$ films; therefore, the SEM images of those specimens are not included in this study. Although the glass-transition temperatures of the composite films increased with an increase of the clay concentration, the poor dispersion of nano-filler seen in the SEM photographs might be the probable reason for the decrease of the storage-modulus values.

\section{CONCLUSIONS}

In the present study the effects of different surfacemodification techniques and filler concentration were examined for nanoclay/PMMA composite films. The films were produced via a solution-casting technique and their behaviours were determined depending on their modification type. Based on the XRD characterization results it was surprising that the presence of silane and surfactant in the nanoclay structure led to the existence/increase of the amorphous phase. Although the main purpose of this work is the application of organophilic modification and silane surface treatment together for combining their synergetic effects, the produced films did not satisfy the expectations in terms of storage modulus $\left(E^{\prime}\right)$. However, the introduction of nanofiller led to an increase of the glass-transition temperatures $\left(T_{\mathrm{g}}\right)$ of almost every composite film, independent of the modification technique. So it was concluded that the addition of a larger nanoclay quantity enhances the adhesion of the polymer and layered silicate. The individual silane agent implementation was the most successful method and the silanized composites generally exhibited the highest stiffness $\left(E^{\prime}\right)$ and transition temperature $\left(T_{\mathrm{g}}\right)$, as compared to the other samples. In addition, the loss modulus $\left(E^{\prime \prime}\right)$ of the every composite film shifted to higher temperatures with an increase of the nanoclay concentration. This may be attributed to the effect of the clay on the relaxation manner of PMMA chains and according to the SEM images, the clay fillers are generally observed as agglomerated particles, but they showed a narrow size distribution and a relatively good regularity.

\section{Acknowledgment}

Funding for this research was provided by the project 2016-069, Scientific Research Funds of Manisa Celal Bayar University.

\section{REFERENCES}

${ }^{1} \mathrm{G}$. Ji, Nanoclay reinforced polymer composite and its application to hybrid composite structures, MSc Thesis, USA, (2008)

${ }^{2}$ S. Ray, A. J. Easteal, Advances in polymer-filler composites: macro to nano, Materials and Manufacturing Process, 22 (2007), 741-749, doi:10.1080/10426910701385366

${ }^{3}$ Q. T. Nguyen, D. G. Baird, Preparation of polymer-clay nanocomposites and their properties, Advances in Polymer Technology, 25 (2006), 270-285, doi:10.1002/adv.20079

${ }^{4}$ M. T. Albdiry, B. F. Yousif, H. Ku, K. T. Lau, A critical review on the manufacturing processes in relation to the properties of nanoclay/polymer composites, Journal of Composite Materials, 47 (2013), 1093-1115, doi:10.1177/0021998312445592

${ }^{5}$ R. Ollier, E. Rodriguez, V. Alvarez, Unsaturated polyester/bentonite nanocomposites: Influence of clay modification on final performance, Composites Part A: Applied Science and Manufacturing, 48 (2013), 137-143, doi:10.1016/j.compositesa.2013.01.005

${ }^{6}$ E. Kaya, M. Tanoglu, S. Okur, Layered clay/epoxy nanocomposites: Thermomechanical, flame retardancy and optical properties, Journal of Applied Polymer Science, 109 (2008), 834-840, doi:10.1002/ app. 28168

${ }^{7}$ A. A. Azeez, K. Y. Rhee, S. J. Park, D. Hui, Epoxy clay nanocomposites - processing, properties and applications: A review, Composites Part B: Engineering, 45 (2013), 308-320, doi:10.1016/j.compositesb.2012.04.012

${ }^{8}$ G. X. Chen, J. S. Yoon, Clay functionalization and organization for delamination of the silicate tactoids in poly(1-lactide) matrix, Macromolecular Rapid Communications, 26 (2005), 899-904, doi:10.1002/marc.200500046

${ }^{9}$ R. Ianchis, M. C. Corobea, D. Donescu, I. D. Rosca, L. O. Cinteza, L. C. Nistor, E. Vasile, A. Marin, S. Preda, Advanced functionalization of organoclay nanoparticles by silylation and their 
polystyrene nanocomposites obtained by miniemulsion polymerization, Journal of Nanoparticle Research, 14 (2012), 1-12, doi:10.1007/s11051-012-1233-6

${ }^{10}$ L. Unnikrishnan, S. Mohanty, S. K. Nayak, A. Ali, Preparation and characterization of poly(methyl methacrylate)-clay nanocomposites via melt intercalation: Effect of organoclay on thermal, mechanical and flammability properties, Materials Science and Engineeering: A, 528 (2011), 3943-3951, doi:10.1016/j.msea.2011.01.071

${ }^{11}$ N. Salahuddin, The effect of polyoxypropylene-montmorillonite intercalates on polymethylmethacrylate, Polymer Composites, 30 (2008), 13-21, doi:10.1002/pc.20520

${ }^{12}$ E. Vasiliu, C. S. Wang, R. A. Vaia, Preparation of optically transparent films of poly(methyl methacrylate) (PMMA) and montmorillonite, Materials Research Society Symposium Proceeding, 703 (2002), 243-248

${ }^{13}$ M. Karesoja, H. Jokinen, E. Karjalainen, P. Pulkkinen, M. Torkkeli, A. Soininen, J. Ruokolainen, H. Tenku, Grafting of montmorillonite nano-clay with butyl acrylate and methyl methacrylate by atom transfer radical polymerization: Blends with poly(BuA-co-MMA), Journal of Polymer Science: Part A: Polymer Chemistry, 47 (2009), 3086-3097, doi:10.1002/pola.23400

${ }^{14}$ M. Kumara, V. Kumara, P. Upadhyayab, G. Pugazhenthia, Fabrication of poly(methyl methacrylate) (PMMA) nanocomposites with modified nanoclay by melt intercalation, Composite Interfaces, 21 (2014), 819-832, doi:10.1080/15685543.2014.961780

${ }^{15}$ X. Huang, W. J. Brittain, Synthesis and characterization of PMMA nanocomposites by suspension and emulsion polymerization, Macromolecules, 34 (2001), 3255-3260, doi:10.1021/ma001670s

${ }^{16}$ K. L. Deng, J. Liu, G. Z. Wang, H. Tian, X. B. Ren, H. B. Zhong, P. F. Zhang, Potassium diperiodatocuprate-mediated preparation of poly(methyl methacrylate)/organo-montmorillonite composites via in situ grafting copolymerization, eXPRESS Polymer Letters, 2 (2008), 677-686, doi:10.3144/expresspolymlett.2008.80

${ }^{17}$ M. Khajehpour, G. A. Gelves, U. Sundarara, Modification of montmorillonite with alkyl silanes and fluorosurfactant for clay/fluoroelastomer (fkm) nanocomposites, Clays and Clay Minerals, 63 (2015), 1-14, doi:10.1346/CCMN.2015.0630101

${ }^{18}$ B. Sharmaa, R. Chhibberb, R. Mehtac, Effect of surface treatment of nanoclay on the mechanical properties of epoxy/glass fiber/clay nanocomposites, Composite Interfaces, 23 (2016), 623-640, doi:10.1080/09276440.2016.1165522
${ }^{19}$ T. Jose, S. C. George, M. G. Maya, H. J. Maria, R. Wilson, S. Thomas, Effect of bentonite clay on the mechanical, thermal, and pervaporation performance of the poly(vinyl alcohol) nanocomposite membranes, Industrial \& Engineering Chemistry Research, 53 (2014), 16820-16831, doi:10.1021/ie502632p

${ }^{20}$ M. E. Penoff, M. Lanfranconi, V. A. Alvarez, R. Ollier, Curing kinetics of epoxy/alkyl phosphonium modified nanoclay composites for high performance applications, Thermochimica Acta, 608 (2015), 20-29, doi:10.1016/j.tca.2015.04.008

${ }^{21}$ H. Assaedi, F. U. A. Shaikh, I. M. Low, Effect of nano-clay on mechanical and thermal properties of geopolymer, Journal of Asian Ceramic Societies, 4 (2016), 19-28, doi:10.1016/j.jascer. 2015.10.004

${ }^{22}$ K. Dean, S. Bateman, R. Simons, A comparitive study of UV active silane grafted and ion exchanged organo-clay for application in photocurable urethane acrylate nano and micro composites, Polymer, 48 (2007), 2231-2240, doi:10.1016/j.polymer.2007.02.044

${ }^{23}$ K. Ratinac, R. Gilbert, L. Ye, A. Jones, S. Ringer, The effects of processing and organoclay properties on the structure of PMMA clay nanocomposites, Polymer, 47 (2006), 6337-6361, doi:10.1016/ j.polymer.2006.07.005

${ }^{24}$ M. M. F. Silva, S. S. S. Gomes, M. G. Fonseca, et al. Synthesis and characterization of a silylated Brazilian clay mineral surface, Chemical Papers, 68 (2014), doi:10.2478/s11696-013-0525-3

${ }^{25} \mathrm{~S}$. Appukuttan, K. Joseph, Immobilizing polymer chains in chlorobutyl rubber nanocomposites, Society of Plastics Engineers Plastics Research Online, 1-2 (2014), doi:10.2417/spepro.005625

${ }^{26}$ J. Tarrío-Saavedra, J. López-Beceiro, S. Naya, C. Gracia, R. Artiaga, Controversial effects of fumed silica on the curing and thermomechanical properties of epoxy composites, eXPRESS Polymer Letters, 4 (2010), 382-395, doi:10.3144/expresspolymlett.2010.48

${ }^{27}$ X. Zhang, L. S. Loo, Study of glass transition and reinforcement mechanism in polymer/layered silicate nanocomposites, Macromolecules, 42 (2009), 5196-5207, doi:10.1021/ma9004154

${ }^{28}$ C. Wan, X. Qiao, Y. Zhang, Y. Zhang, Effect of different clay treatment on morphology and mechanical properties of PVC-clay nanocomposites, Polymer Testing, 22 (2003), 453-461, doi:10.1016/ S0142-9418(02)00126-5

${ }^{29}$ C.-W. Chiu, J.-J. Lin, Self-assembly behavior of polymer-assisted clays, Progress in Polymer Science 37 (2012), 406-444 